\title{
"Everything the hujur tells is very educative but if I can't not apply those in my own life then there is no meaning": A mixed-methods process evaluation of a smoke-free homes intervention in Bangladesh.
}

Cath Jackson ( $\square$ cath@validresearch.co.uk)

University of York

Zunayed Al Azdi

ARK Foundation

Ian Kellar

University of Leeds

Noreen Dadirai Mdege

University of York

Caroline Fairhurst

University of York

Tarana Ferdous

ARK Foundation

Catherine Hewitt

University of York

Rumana Huque

ARK Foundation

Anna-Marie Marshall

University of York

Sean Semple

University of Stirling

Aziz Sheikh

University of Edinburgh

Kamran Siddiqi

University of York

\section{Research Article}

Keywords: tobacco, second-hand smoke, smoke free homes, faith, mosque, intervention, process evaluation, Bangladesh 
Posted Date: November 17th, 2021

DOI: https://doi.org/10.21203/rs.3.rs-1071655/v1

License: (c) (i) This work is licensed under a Creative Commons Attribution 4.0 International License. Read Full License 


\section{Abstract}

Background Exposure to second-hand smoke from tobacco is a major contributor to global morbidity and mortality. A cluster RCT in Bangladesh concluded a community-based smoke-free home (SFH) intervention delivered in mosques, with or without indoor air quality (IAQ) feedback to households was neither effective nor cost-effective compared to no intervention. This paper presents the process evaluation embedded within the trial. Methods A mixed method process evaluation comprising interviews with 30 household leads and six imams, brief questionnaire administered to 848 household leads, fidelity assessment of intervention delivery in six mosques and research team records. Data sets were triangulated using meta-themes informed by three process evaluation functions: implementation, mechanisms of impact and context. Results IMPLEMENTATION: The frequency of SFH intervention delivery was judged moderate to good. However there were mixed levels of intervention fidelity and poor reach. Ayahs-messages targeting SHS attitudes were most often fully implemented and had greatest reach (with social norms). Frequency and reach of IAQ feedback intervention were good. MECHANISMS OF IMPACT: Both interventions had good acceptability. However, views on usefulness of the interventions were mixed. Only half of households reported achieving a SFH home at 3-months follow-up. Individual drivers to behaviour change were new SFH knowledge with corresponding positive attitudes, social norms and intentions. Individual barriers were a lack of self-efficacy and plans. CONTEXT: Social context drivers to SFH intervention implementation in mosques were in place and important. No context barriers to implementation were reported. Social context drivers to SHS behaviour change were children's requests. Barriers were a reluctance to request visitors to smoke outside. (Not) having somewhere to smoke outside was a physical context (barrier) and driver. Conclusions Despite detailed development and adaption work with relevant stakeholders, the SFH and IAQ interventions became educational interventions that were motivational but insufficient to overcome significant context barriers to SHS behaviour change. Embedding these interventions into community wide strategies that include practical cessation support and enforcement of SFH legislation is needed.

\section{Background}

Exposure to second-hand tobacco smoke (SHS) is estimated to cause 1.2 million deaths and the loss of 11 million disability-adjusted life years worldwide every year [1]. Our focus was Bangladesh and the concerning levels of SHS exposure in homes. In a recent study of 1746 households in Mirpur, Dhaka, over half (55\%) self-reported that smoking by household members and visitors was permitted inside the home [2]. Cotinine (a metabolite of nicotine and an indicator of tobacco smoke exposure) was detected in the saliva of $95 \%$ of children aged 9-11 years in a school-based survey suggesting that children are commonly exposed to SHS in Dhaka, Bangladesh [3]. Unfortunately, evidence of effective interventions in South Asia to reduce SHS exposure in the home, including adaption of interventions found to be effective elsewhere (typically in high income countries), is lacking [4-6] Moreover, poor reporting of interventions means that the elements with greatest efficacy are difficult to identify [4-6]. 
International scientific literature shows an association between religious faith and smoking behaviours [7-13] with proposed mechanisms including the idea of leading a "puritanical" life, having spiritual strength to resist temptations for future benefit, and being part of a social network of people who lead a healthy life. Relatedly, religious leaders are often highly respected and trusted by their communities [813]. Together, these suggest that religious teachings, settings and leaders offer potential to deliver tobacco control interventions.

In Bangladesh, $89 \%$ of the population is Muslim [14]. The teachings of Islam focus on the principles of minimising harm to individuals and society; and maximising the opportunities for individual and collective well-being [10]. As such, smoking is discouraged, although whether it is decreed as mukrooh (discouraged) or haram (prohibited) varies [10]. To date, very few evaluations of Islamic faith-based interventions targeting smoking behaviours have been undertaken $[12,15,16]$.

A 2018 Cochrane review of interventions to promote smoke-free homes (SFH) reported that 24 of 78 included studies found statistically significant reductions in children's SHS exposure [4]. No one intervention strategy was clearly identified as the gold standard. Successful strategies included motivational interviewing, brief counselling, nicotine replacement therapy for smoking cessation for parents who smoke, and feedback on markers of children's exposure to SHS including the use of indoor air quality (IAQ) feedback. IAQ feedback offers participants objectively measured information on the impact that smoking has on concentrations of air pollutants in their homes to motivate them to reduce or stop smoking inside. It has been effective in reducing SHS in homes and/or children's biomarkers of SHS exposure in several trials in a range of settings and formats, including immediate and delayed feedback [17-23].

We conducted a three-arm cluster randomised controlled trial, MCLASS (Muslim Communities Learning About SHS) II, in the Mirpur area of Dhaka, Bangladesh, to evaluate the effectiveness and costeffectiveness of a community-based SFH intervention delivered in mosques with or without IAQ feedback in reducing exposure to SHS in the home $[24,25]$. The SFH and IAQ interventions are described in Figure 1. The trial found that the SFH intervention, with or without IAQ feedback, was neither effective nor costeffective compared to no intervention. We concluded that these interventions could not be recommended for Bangladesh [24]. In this paper, we present the findings from our embedded process evaluation which investigated implementation, contextual factors, and the mechanisms of impact of the two interventions [26], to understand their lack of influence on trial outcomes.

Figure 1 in here

\section{Methods}

\section{Overview of study design}

This was a mixed method process evaluation conducted November 2018 to January 2019. It comprised interviews with household leads and imams, a brief questionnaire administered to household leads, 
fidelity assessment of intervention delivery and research team records. Findings from the different data sets were triangulated using meta-themes [29] based on the UK Medical Research Council's [26] three process evaluation functions:

- Implementation - what is delivered (frequency, fidelity, reach)?

- Mechanisms of impact - how does the delivered intervention produce change? (intervention acceptability, individual barriers and drivers to SHS behaviour change, self-reported behaviour change)

- Context - how does context affect implementation and outcomes? (social and physical context barriers and drivers to intervention implementation, and to SHS behaviour change)

SHS behaviour change included smokers not smoking inside the home and non-smokers requesting residents and visitors to smoke outside.

\section{Interviews}

\section{Participants}

Semi-structured interviews with 30 household leads living in the catchment areas of 30 mosques (14 allocated to SFH arm, 16 allocated to SFH+IAQ arm) were undertaken post-intervention (at 3-month follow-up). Participants were purposively selected to include men and women, smokers and non-smokers, and different self-reported levels of smoking in the home at 3-month follow-up (see Table 1). Imams who delivered the SFH intervention in six randomly selected mosques (3 from each intervention arm) were interviewed once their intervention delivery was complete.

Two-thirds of household leads were men $(n=20)$, and a similar proportion were aged 45 years or younger $(n=21)$. Over two-thirds $(n=24)$ had no/only primary education. At baseline, all men self-reported as smokers; no women were smokers, but all households had at least one resident smoker to be eligible for the trial, usually the husband or son. About two-thirds of participants $(n=19)$ self-reported that their homes had become smoke-free by 3-month follow-up, defined as not permitting residents or visitors to smoke inside the home. The rest $(n=11)$ self-reported some smoking still occurred at home. 
Table 1

Demographic characteristics and smoking/SFH status of interview participants

\begin{tabular}{|c|c|c|c|c|c|c|c|}
\hline \multirow[t]{2}{*}{ Characteristic } & & \multicolumn{2}{|l|}{$\begin{array}{l}\text { SFH } \\
(n=14)\end{array}$} & \multicolumn{2}{|c|}{$\begin{array}{l}\text { SFH+IAQ } \\
(n=16)\end{array}$} & \multicolumn{2}{|l|}{$\begin{array}{l}\text { All } \\
(n=30)\end{array}$} \\
\hline & & $\begin{array}{l}\text { Men } \\
(n=10)\end{array}$ & $\begin{array}{l}\text { Women } \\
(n=4)\end{array}$ & $\begin{array}{l}\text { Men } \\
(n=10)\end{array}$ & $\begin{array}{l}\text { Women } \\
(n=6)\end{array}$ & $\begin{array}{l}\text { Men } \\
(n=20)\end{array}$ & $\begin{array}{l}\text { Women } \\
(n=10)\end{array}$ \\
\hline \multirow[t]{4}{*}{ Age, years } & $18-25$ & 2 & 0 & 0 & 0 & 2 & 0 \\
\hline & $26-35$ & 5 & 1 & 5 & 0 & 10 & 1 \\
\hline & $36-45$ & 2 & 2 & 1 & 3 & 3 & 5 \\
\hline & $>45$ & 1 & 1 & 4 & 3 & 5 & 4 \\
\hline \multirow[t]{5}{*}{$\begin{array}{l}\text { Education, total } \\
\text { years }\end{array}$} & $\begin{array}{l}\text { No education } \\
(0)\end{array}$ & 1 & 2 & 3 & 2 & 4 & 4 \\
\hline & Primary (1-5) & 4 & 1 & 4 & 3 & 8 & 4 \\
\hline & $\begin{array}{l}\text { Secondary (6- } \\
\text { 10) }\end{array}$ & 2 & 1 & 3 & 1 & 5 & 2 \\
\hline & $\begin{array}{l}\text { Higher } \\
\text { secondary } \\
(10-12)\end{array}$ & 2 & 0 & 0 & 0 & 2 & 0 \\
\hline & $\begin{array}{l}\text { University } \\
(>12)\end{array}$ & 1 & 0 & 0 & 0 & 1 & 0 \\
\hline \multirow{2}{*}{$\begin{array}{l}\text { Smoking status (at } \\
\text { baseline) }\end{array}$} & Smoker & 10 & 0 & 10 & 0 & 20 & 0 \\
\hline & Non-smoker & 0 & 4 & 0 & 6 & 0 & 10 \\
\hline \multirow{3}{*}{$\begin{array}{l}\text { Smoking in the } \\
\text { home (3-month } \\
\text { follow-up) }\end{array}$} & $\begin{array}{l}\text { Nobody } \\
\text { smoking }\end{array}$ & 7 & 3 & 6 & 3 & 13 & 6 \\
\hline & $\begin{array}{l}\text { Still some } \\
\text { smoking }\end{array}$ & 3 & 1 & 3 & 2 & 6 & 3 \\
\hline & $\begin{array}{l}\text { Lots of } \\
\text { smoking }\end{array}$ & 1 & 0 & 0 & 1 & 1 & 1 \\
\hline
\end{tabular}

All six imams were non-smokers (a pre-requisite of their mosque's inclusion in the trial). They had been an imam for between 6 and 35 years, and 2 to 22 years in their current mosque. The size of their congregation during Jumu'ah prayers varied from 800 to 4500 men.

Data collection 
The interviews were conducted in Bangla face-to-face in the interviewee's home or at the mosque. All participants provided written informed consent before the interview commenced. Interviews with household leads explored their and their family members' interaction with the SFH/IAQ feedback interventions, views about the intervention(s), impact on their/their family members' SHS behaviours as well as individual or context barriers and drivers to creating a SFH (Figure 2). These lasted 8-27 minutes. Interviews with imams explored acceptability of the SFH intervention, and experiences of delivery including individual or context barriers and drivers. These lasted 25-53 minutes. All interviews were digitally audio-recorded.

Figure 2 in here

\section{Data analysis}

The interviews were transcribed verbatim, translated into English and checked by the interviewers. The data were subjected to thematic analysis using the Framework approach [30], which is designed to address policy and programme-related questions. Excel 365 was used to facilitate data management.

An English language thematic framework was developed for each data set based on the study research questions, topic guides and a sample of randomly selected interview transcripts (seven - household lead, two - imam); then piloted with more transcripts (three -household lead, one - imam) before finalising. The interview data were then systematically charted into the relevant frameworks. Summaries of responses from participants and verbatim quotes were entered. Both sets of charted data were then reviewed and interrogated to compare views, seek patterns, connections, and explanations within the data. Descriptive findings documents were written for both data sets.

\section{Questionnaire}

\section{Participants and data collection}

All household leads in the two intervention arms (SFH: 387 men, 33 women; SFH+IAQ: 461 men, 19 women) completed a short process evaluation questionnaire, administered face-to-face by a researcher post-intervention (at 3-month follow up). It asked questions on which components of the SFH/IAQ feedback interventions participants had received, perceived intervention usefulness and SHS behaviour change.

\section{Data analysis}

$\mathrm{Yes} / \mathrm{no} / \mathrm{don}$ 't know responses were used for the intervention receipt questions. Perceived intervention usefulness was scored on a 7-point Likert scale from 1 (not at all useful) to 7 (extremely useful). Scores of 5 and above were classified as useful. Three response options were offered for SHS behaviour change: nobody smokes inside the home anymore/there is still some smoking inside the home, but it is less than before/there is still lots of smoking inside the home. Frequency and proportion $(\mathrm{N}, \%)$ were calculated for each receipt question, not useful/useful and the three SHS behaviour change categories. 


\section{Fidelity assessment}

\section{Data collection}

Delivery of the SFH intervention during Friday Jumu'ah prayers was observed in six randomly selected mosques. Trained researchers conducted these checks and completed a fidelity index. Imams had previously received training and guidance on Ayah-message delivery. They were unaware that they were being observed. In three mosques, delivery of the Ayahs-messages scheduled for odd numbered weeks $(1,3,5$ etc.) were checked. In the other three mosques, the Ayahs-messages scheduled for even numbered weeks (2,4,6 etc.) were checked. Each item in the index corresponded with the 12 weeks of Ayahsmessages targeting five key barriers/drivers to SHS behaviours (see Figure 2). Delivery of each Ayahmessage was scored 0-not implemented, 1-Ayah recited with no message, 2-Ayah recited with partial explanation of message, 3-Ayah recited with more than partial explanation but not full explanation of message, and 4-fully implemented. Definitions were provided for each Ayah-message (available from authors on request).

Data analysis

For each mosque, a total fidelity score was computed by summing the scores for Ayahs-messages from 0 (did not implement any Ayahs-messages) to 24 (all assessed Ayahs-messages were fully implemented). For each target barrier/driver (Figure 2), we counted the number of times the Ayah-message was fully/partially/not implemented and divided this by the total number of opportunities for full implementation, for example, for "attitude" total number is 12 (3 mosques x 4 Ayahs-messages).

\section{Research team records}

\section{Data collection}

Records were collected from mosques on their self-reported delivery of the SFH intervention. Field investigators self-recorded delivery of the IAQ feedback and a signature from the recipient was collected. Data analysis

Counts and percentages $(\mathrm{N}, \%)$ were calculated for both delivery items.

\section{Triangulating findings}

To triangulate the findings from the different datasets, the key findings for each intervention (SFI, IAQ feedback) from each dataset were displayed in a triangulation matrix organised by three meta-themes [29] (process evaluation functions): implementation, mechanisms of impact and context [26]. For each meta-theme, one or more datasets provided findings. Where there was more than one, these were compared to consider if they were convergent (in agreement), complementary (partial agreement), contradictory (disagreement) or silent (findings do not occur in a dataset but may have been expected to 
do so) [29]. The triangulation matrices for the SFH intervention and IAQ feedback are provided in Additional Files 1 and 2.

\section{Findings}

Findings from the four data sets (interviews, brief questionnaire, fidelity assessment, research team records) are organised by the three meta-themes [29]: implementation, mechanisms of impact and context [26]. A conclusion statement for each meta-theme is presented, followed by the data informing that conclusion.

\section{Implementation}

\section{The frequency of SFH intervention delivery was judged moderate to good. There were mixed levels of intervention fidelity and poor reach. Ayahs-messages targeting attitudes were most often fully implemented and had greatest reach (with social norms).}

Records showed that 29 of the 30 mosques (97\%) reported delivering all 12 weeks of the SFH intervention. The other mosque delivered 10 weeks. Imams who were interviewed typically reported that they had delivered "almost all" of the SFH intervention as instructed, during Jumu'ah prayer, before Khutbah, usually for 5-10 minutes. Two admitted to not delivering all 12 weeks, one of whom had left to perform Hajj in Makkah, offering that he had delivered $60 \%$. All described using other opportunities to share the Ayahs-messages in the mosque. Examples included in the Madrasas, and during monthly parent meetings, Qur'an classes and other religious congregations, such as Mahfils (gathering of community people to listen to religious teachings), Maghrib (evening) prayers and Isha (late evening) prayers.

Whilst these convergent record and interview data indicated moderate-to-good frequency of intervention delivery, the questionnaire data revealed poor intervention reach. Only half of men in the two intervention arms reported receiving the SFH intervention (SFH 49.4\%; SFH+IAQ 55.5\%). Women typically did not attend Friday prayers in the mosques in Bangladesh, so were asked if any of their family members had heard the Ayahs-messages. Once again, only half reported yes (SFH 51.5\%; SFH+IAQ 52.6\%). The interview data were more positive. All but three men reported having received the SFH intervention and all but one woman were aware of family members receiving it. For those men whom the intervention did reach, this was during Friday Jumu'ah prayers (SFH 99.5\%; SFH+IAQ 99.6\%), with 100\% of women mentioning this for their family members. Less than $3 \%$ of men reported receiving the SFH intervention in other mosque sessions. This reach via Friday prayers was confirmed in the interview data, thus both data sets supported the imams' delivery accounts.

Yes, that if I smoke in the presence of my family and my children then it will be harmful for them too. Imam of mosque told it. He said "If you want to smoke, don't do it at your home. Yet it is best not to smoke." The imam said directly, "Never smoke at home." When he was delivering Khutbah, that time he talked about it. 
[Man, SFH intervention, nobody smokes in home at 3-month follow-up]

Yes. I have come to know about it from my younger son. He goes to Jumu'ah always. I need not send him, he goes for his prayers by himself. Hujur tells many Hadith and gives speeches on smoking. [Woman, SFH intervention, nobody smokes in home at 3-month follow-up]

Regarding the detail of what was delivered by the imams, the mean fidelity score across six mosques was 19.6 (SD 2.51, range 16-22 of maximum 24). Ayahs-messages that were best delivered targeted attitudes and were $75.0 \%$ fully implemented. Ayahs-messages targeting self-efficacy and coping planning were $66.67 \%$ fully implemented. Ayahs-messages targeting social norms and intention formation-action planning were only $50.0 \%$ fully implemented (see Table 2 ).

Table 2

Fidelity to delivery of SFH intervention

\begin{tabular}{|c|c|c|c|c|c|c|}
\hline \multirow[b]{2}{*}{ Target barrier/driver, $\mathrm{n}$ (\%) } & \multicolumn{6}{|c|}{ Level of implementation (\%) } \\
\hline & Full & $\begin{array}{l}\text { Partial - } \\
\text { level } 3\end{array}$ & $\begin{array}{l}\text { Partial - } \\
\text { level } 2\end{array}$ & $\begin{array}{l}\text { Partial - } \\
\text { level } 1\end{array}$ & $\begin{array}{l}\text { Not } \\
\text { implemented }\end{array}$ & $\begin{array}{l}\text { No } \\
\text { data }\end{array}$ \\
\hline Attitude, $n=12$ & $\begin{array}{l}9 \\
(75.0)\end{array}$ & $1(8.3)$ & $0(0.0)$ & $1(8.3)$ & $1(8.3)$ & $\begin{array}{l}0 \\
(0.0)\end{array}$ \\
\hline Self-efficacy, $n=6$ & $\begin{array}{l}4 \\
(66.7)\end{array}$ & $1(16.7)$ & $1(16.7)$ & $0(0.0)$ & $0(0.0)$ & $\begin{array}{l}0 \\
(0.0)\end{array}$ \\
\hline Coping planning, $n=6$ & $\begin{array}{l}4 \\
(66.7)\end{array}$ & $1(16.7)$ & $1(16.7)$ & $0(0.0)$ & $0(0.0)$ & $\begin{array}{l}0 \\
(0.0)\end{array}$ \\
\hline Social norms, $n=6$ & $\begin{array}{l}3 \\
(50.0)\end{array}$ & $0(0.0)$ & $1(16.7)$ & $0(0.0)$ & $1(16.7)$ & $\begin{array}{l}1 \\
(16.7)\end{array}$ \\
\hline $\begin{array}{l}\text { Intention formation - } \\
\text { action planning, } n=6\end{array}$ & $\begin{array}{l}3 \\
(50.0)\end{array}$ & $3(50.0)$ & $0(0.0)$ & $0(0.0)$ & $0(0.0)$ & $\begin{array}{l}0 \\
(0.0)\end{array}$ \\
\hline \multicolumn{7}{|c|}{$\begin{array}{l}\text { Note. Delivery of each Ayah-message was scored } 0 \text {-not implemented, } 1 \text {-Ayah recited with no } \\
\text { message, } 2-\text { Ayah recited with partial explanation of message, } 3 \text { - Ayah recited with more than partial } \\
\text { explanation but not full explanation of message, } 4 \text {-fully implemented. Ayahs-messages linked to } \\
\text { attitudes were scheduled for delivery in four weeks. The other four target barriers/drivers were } \\
\text { scheduled for two weeks each. a No assessment as this was scheduled during the Eid festival. }\end{array}$} \\
\hline
\end{tabular}

Interview and questionnaire data partially confirmed this. Imams described focusing particularly on the Ayahs-messages about the risks of SHS to children, pregnant women, and others (targeting attitudes and social norms). This preference did not seem to be related to the ease/difficulty of delivering the different Ayahs-messages (they were confident with all 12). Instead, their perception was that their congregation were interested in learning about this, given that it is not usually spoken about in the mosques. 
These were also the Ayahs-messages that men most recalled hearing (79.1-94.8\%, see Figure 3). All but three men interviewed mentioned hearing Ayahs-messages about the risks of SHS, citing the dangers of polluting their home and damaging the health of their family, particularly their children. Most also remembered the clear direction from the imam within these Ayahs-messages to stop smoking near other people.

If I smoke, people who are around me are also harmed. Cause when I breathe out the smoke, the people around inhale the oxygen or the air, they are also harmed. They are harmed more than me. Then it is seen, when a child is born or a woman is pregnant, smoking harms her children.

[Man, SFH intervention, nobody smokes in home at 3-month follow-up]

He [the imam] said "If you want to smoke, don't do it at your home. Yet it is best not to smoke."[Man, $\mathrm{SFH}+\mathrm{IAQ}$, nobody smokes in home at 3-month follow-up]

Noticeably less well recalled by men were Ayahs-messages targeting self-efficacy, coping planning and intention formation (37.5-45.0\%, see Figure 3). Just five men who were interviewed mentioned that the imam provided guidance on "how" to change their smoking behaviours, whilst a similar minority declared the imam provided no advice at all.

Finally, the intention was that 100 copies of a short SFH booklet would be distributed in each mosque, thus reaching 3,000 households in total. The consensus amongst the imams was that the booklets were popular, copies were distributed quickly, and more were needed. Some had targeted smokers, elders, or people they considered to be educated who would most benefit from it.

We can understand who smokes. We tried to give it to them. Besides them, there are many educated people who want to know about it. We distributed among those educated and smokers. Children or those who don't understand it or don't have the concern for it yet, we didn't give to them. [Imam 2]

The interview data suggested that reach of the booklet was poor. Notably no men interviewed reported receiving it and this interview question prompted some to say they could not have read it anyway. Three women mentioned that their sons had brought the booklet home, two of whom could not read. One reported that her children had read it.

We have received it, but we could not understand what the booklet was about, so we have thrown it away. We are women so we don't understand all these things.

[Woman, SFH+IAQ, nobody smokes in home at 3-month follow-up]

\section{Frequency and reach of IAQ feedback intervention were good. Fidelity was not assessed.}

Research team records that included a signature from households showed that IAQ feedback was delivered to all 640 households $(100 \%)$ in that trial arm indicating good intervention frequency. Good reach was also achieved with $98.9 \%$ of household leads and 13 of 15 interview participants reporting 
having received the IAQ feedback. Half of interview participants mentioned that another family member, for example their wife, husband or child had been the ones to receive the report. A few commented that they could not read the IAQ report, relying on others to do this for them.

Nobody can read in the home. The youngest daughter read it us twice or three times. After her departure, we were unable get information from it.

[Man, SFH+IAQ, nobody smokes in home at 3-month follow-up]

\section{Mechanisms Of Impact}

\section{Good acceptability of SFH intervention, drivers were new SFH knowledge with corresponding positive attitudes, social norms and intentions. Barriers were a lack of self-efficacy and plans.}

The male household lead and imam interview data were convergent indicating good acceptability of the SFH intervention. The consensus amongst the men was that listening to the messages in the mosque "felt good", informed them and motivated them to change their smoking behaviours.

I felt deeply pleased because the message of the imam melts everyone's heart. I felt like if I could give up smoking from today.

[Man, SFH intervention, nobody smokes in home at 3-month follow-up]

There was one exception, a man who was not interested in the intervention, suggesting that he already knew this information anyway.

Hujur has mentioned some Ayahs about smoking. But I did not pay much attention to it. I have enough knowledge about it and I did not find much interest knowing details of it. [Man, SFH intervention, nobody smokes in home at 3-month follow-up]

The imams were also very enthusiastic. Their perception was that the Ayahs-messages were well received by their congregations, and the SFH intervention was useful and appropriate.

I believe that this is a very useful intervention and it is praiseworthy. The objectives are very helpful for our society and it is a responsibility for us all to ensure that the objectives are properly enforced. From Islamic approach and societal approach, this intervention is praiseworthy on both fronts. [Imam 4]

They also observed that delivering the messages during Jumu'ah prayer was the right thing to do as that is when the mosque was most crowded, would reach large numbers of people and potentially have greatest impact.

The Jumu'ah prayer time is the most suitable time for it because what I have seen in my 22 years' experience as an imam is that approximately $90 \%$ of people of our society attends Jumu'ah prayer even though they do not perform the rest of the prayers. The best time to discuss it is the time before Khutbah 
as there is no chance to discuss these topics after the Jumu'ah prayer. Not all the partakers are present when the Jumu'ah speech starts around 12.25 or 12.30 pm but they are before the Khutbah. [Imam 5]

The proposed individual drivers of behaviour change were attitudes, self-efficacy, social norms, intention formation and planning (see Figure 2). We explored the household leads' interview data for evidence of these. Men's accounts clearly illustrated a development in their knowledge and a shift in their attitudes and social norms about SHS, from the messages delivered in the mosque (further confirming the recall data above). In fact, SHS and the risks to others appeared to be new information for most of the men, eliciting beliefs about the social consequences of their smoking, especially the potential harm they were doing to their children. Several participants, both men and women, talked about the idea of having fresh air to breath, healthier children, and no bad smell in the house.

If I want to keep my children healthy and safe then it is best for me to quit smoking completely. He also said to advise others who smoke to quit as well since it does harm those around you, particularly the children. Smoking is harmful for oneself and their families. [Man, SFH intervention, still some smoking in home at 3-month follow-up]

I think that if I quit it will benefit everyone, not just one person. The smoke and smell will not affect anyone if there is no one smoking at all.

[Man, SFH intervention, still some smoking in home at 3-month follow-up]

Amongst many men, there was evidence of an intention to act, prompted by the words of the imam and a corresponding new awareness of the concept of SHS.

It was mostly due to the hujur's speech that inspired me. He always speaks to us keeping our best interest in mind. He refers to Hadith so that we know what is best for our Muslim community. I liked his messages very much and realized that it is for the best that I should try to stop smoking at home.

[Man, SFH+IAQ, lots of smoking in home at 3-month follow-up]

Notably whilst these men appeared motivated to change their behaviour, they did not really speak of their plans for translating their intention into action or their self-efficacy in doing this. Just one man explicitly spoke of his confidence in creating a SFH, instilled by the imam.

Well, my confidence has been brought by the imam [belief] inside of us.

[Man, SFH+IAQ, still some smoking in home at 3-month follow-up]

Conversely, the three men who were not motivated by the imam to change, all alluded to a lack of strategies and low self-efficacy referring to their addiction and stress. One had previously failed to quit smoking. Another stated that he never listens to the imam because he felt unable to apply this "education" into his life. 
Look everything that the hujur tells is very educative. Each of his sentence is educative. If he tells anything regarding smoking, it is even educative. We all actually know it but how many of us listen to it? If I cannot apply those in my own life, then there is no meaning of this educative lines. I never pay attention to the hujur's speech.

[Man, SFH intervention, nobody smokes in home at 3-month follow-up]

\section{Good acceptability of IAQ intervention, drivers were new SFH knowledge with drivers were new SFH knowledge with corresponding positive attitudes, social norms and intentions. Barriers were a lack of plans.}

The IAQ machine, report and subsequent conversation with the field investigator were well received. They were seen by household leads who were interviewed, to educate people for the first time on the dangerous situation regarding air pollution in their home, and prompting intentions to create a SFH.

I like the way you provide us report. It's a systematic way. They made us understand very clearly with the help of that report. It was shown how smoking is causing harm. That's why I liked it most. [Man, SFH+IAQ, nobody smokes in home at 3-month follow-up]

Many interviewed household leads commented that the machines should be installed in more households to educate more families and protect more children from SHS.

Try to continue it. Try to do it for ten more people, try to bring good for those extra ten people so that more people get benefits. Try to help some more children.

[Woman, SFH intervention, nobody smokes in home at 3-month follow-up]

As with the SFH intervention, interviewees' accounts illustrated a development in SHS knowledge and a shift in their beliefs, attitudes and social norms. Approximately half the men and women interviewed spoke of learning that the air pollution was at levels there were dangerous to their family's health; and the importance of the smoker going outside or away from other people to smoke.

We learnt from your initiative and nice report. We realized that it actually harms our health or the children's health. So, it is better not to smoke. Even if I have to smoke, I can do it outside home. [Man, SFH+IAQ, nobody smokes in home at 3-month follow-up]

This new understanding elicited strong beliefs about the importance of having of a SFH, particularly in terms of improving their children's health. A few spoke of how the personalised feedback had "scared" smokers (the men themselves and family members) into action.

The environment is good. It is good for our health. It is good for our children. Children don't suffer from coughing. Children start coughing because of cigarette smoke. They start coughing. All those problems are solved. 
[Woman, SFH+IAQ, nobody smokes in home at 3-month follow-up]

After this machine was set here, we felt one kind of fear in us and in our children as well. They are afraid of it thinking, "If we smoke then something bad might happen to us", so we will not smoke. [Woman, $\mathrm{SFH}+\mathrm{IAQ}$, nobody smokes in home at 3-month follow-up]

All participants had positive intentions to create a SFH following their IAQ feedback.

You made me understand the facts while visiting my home and when I saw the facts with proof in my own eyes then I thought it's better to give up this habit.

[Man, SFH+IAQ, nobody smokes in home at 3-month follow-up]

Consistent with the SFH intervention, there was no mention of specific strategies that the men planned to use to avoid smoking in the home or negotiation strategies that family members could use.

\section{Mixed views on usefulness of SFH intervention. Moderate usefulness of IAQ intervention. Only half of households reported achieving a SFH home.}

Despite good acceptability of the SFH and IAQ interventions and interview evidence of changes in knowledge, attitudes and social norms leading to an intention to create a SFH, questionnaire data on the "usefulness" of the two interventions were less positive. Amongst men who reported receiving the SFH intervention 38.2\% (SFH) and 79.2\% (SFH+IAQ) said it was useful in helping their family achieve a SFH, whilst $60.1 \%$ of household leads (men and women) found the IAQ feedback useful. Furthermore, convergent questionnaire (see Figure 4) and interview data both indicated that only half of households reported having a SFH at three months post-intervention.

In line with the data on drivers above, interview participants considered this to be prompted by new knowledge about the risks of SHS to their family from the imam's messages, strengthened for some by the evidence presented in the IAQ report.

Before when we smoked and someone else came and stood near us we did not feel bad about it. Now we don't do that. We are more attentive about it.

[Man, SFH+IAQ, nobody smokes in home at 3-month follow-up]

Imam said smoking was bad. Then after installing the machine, I realized that the situation was too bad. Other things weren't identified by tests, this was.

[Man, SFH+IAQ, still some smoking in home at 3-month follow-up]

Finally, just a small minority of interview participants mentioned that they now request other visitors to their home not to smoke indoors. 
I told them that I don't smoke inside my house, so you are not allowed to smoke here. If you want, you may do this outside of my house.

[Man, SFH intervention, still some smoking in home at 3-month follow-up]

This had resulted in one woman's brother no longer coming to the house. However, one man continued to permit "special guests" to smoke in his home.

\section{Context}

Social context drivers to SFH intervention implementation were in place and important. No context barriers to implementation were reported.

The consensus amongst the imams was that they had faced no barriers in delivering the SFH intervention. Social context seemed important. Permission from the Islamic Foundation was acknowledged as crucial to demonstrate acceptance of the intervention and a united approach across mosques. Within their own mosques, imams had felt supported by their mosque committees in the form of approval for the topics and messages, rather than any hands-on help. One valued sharing intervention delivery with a khatib, and another would have liked to have ongoing collaboration about delivery with imams from other mosques.

We know about each other's training. So, it can be discussed with him how it can be presented in front of the society grandly. But I have no companion. [Imam 2]

\section{Context barriers/drivers to IAQ intervention implementation were not assessed.}

IAQ frequency and reach data suggested that there were no context barriers to implementation.

\section{Social context drivers to SHS behaviour change were children's requests. Barriers were a reluctance to request visitors to smoke outside. (Not) having somewhere to smoke outside was a physical context (barrier) and driver.}

Social and physical context barriers and drivers to SHS behaviour change emerged from household lead interview data. The key social driver to men smoking outside was having children in the home, with children's direct requests providing further influence.

It is important when my daughter says, "Father, please do not smoke and even if you need to then smoke outside the home. Do not smoke in front of me." Is it not an important thing when the daughter calls her father? [Man, SFH intervention, nobody smokes in home at 3-month follow-up]

Conversely, a social context barrier identified by a few men and women was a reluctance ask all guests to smoke outside. Others were happy to do so, confirming the mixed behaviour change data above.

I usually tell them not to smoke inside the house, but if it's a special guest then they are allowed. 
[Man, SFH intervention, nobody smokes in home at 3-month follow-up]

An additional perspective on social context was offered by several imams. They advocated taking a broader societal approach to enhance message exposure and impact by involving the media and the internet, engaging other institutions such as schools and workplaces, and additional influential community leaders like politicians and celebrities.

I think that if you can include those who are in charge of making decisions in a society, community leaders, as well as committee of the mosques, then this will be more effective. Political leaders have a lot of influence over many in our society. If you can include them somehow then I think your intervention will have better impact. [Imam 1]

If you can look for these celebrities and large gatherings where multiple speakers offer their speech, there are minimum two to three spokesman in these gatherings, you can reach a huge audience by building up relationship with them to briefly include this topic in his speech. He will proceed the discussion according to his rules but if he includes some important facts about smoking, it will be better according to me. [Imam 5]

Finally, physical context was also a driver and barrier to SHS behaviour change. Most men readily identified other places they could smoke, mentioning the road, at work or outside the shop where they bought their products. There were two exceptions. One man complained he had nowhere to smoke outside late at night because the gates to his compound are locked. Another did not want the shame of being seen smoking by other people.

When I work at night and stay up late, the gates are locked by 11 or 11,30. I don't go out then. I smoke at home. [Man, SFH+IAQ, still some smoking in home at 3-month follow-up]

I do not smoke outside at all. If I smoke outside now, people would say, "Uncle, as you are an elderly person, you should not smoke." It is a matter of shame, thus, I do not smoke at all outside. [Man, $\mathrm{SFH}+\mathrm{IAQ}$, nobody smokes in home at 3-month follow-up]

\section{Discussion}

Process evaluations provide useful insight into the effectiveness (or not) of complex health interventions [26]. This can be particularly helpful where the evidence of their impact is mixed or indeed, as for the SFH and IAQ feedback interventions, is absent [24]. Our investigation into the implementation, mechanisms of impact and context [26] of the two interventions uncovered several explanations for their lack of effectiveness in reducing exposure to SHS in the home. In short, evidence of implementation of the SFH intervention in the mosques was mixed, and good for IAQ feedback. Both interventions had high acceptability but mixed perceptions of usefulness with only half of households reporting a SFH home at 3-months follow-up. Household leads described new SFH knowledge with corresponding positive attitudes, social norms and intentions, whilst self-efficacy and plans were lacking. Context for behaviour 
change was both positive (e.g. children's requests to smoke outside, places to smoke) and negative (e.g. reluctance to request visitors to smoke outside, nowhere to smoke outside).

\section{Strengths and limitations}

Our mixed method process evaluation comprised four data sets (interviews, brief questionnaire, fidelity assessment, research team records) that were triangulated to elucidate three key process evaluation functions (implementation, mechanisms of impact, context [26]) for the SFH and IAQ feedback interventions. This approach ensured a comprehensive evaluation drawing on recommendations for good practice for triangulating data [29] and process evaluations [26]. Within and across meta-themes, triangulating data sets afforded confidence in our conclusions.

There were some gaps. Context barriers/drivers and fidelity for IAQ delivery were not assessed. The 100\% frequency and $98.9 \%$ reach data suggest there were limited/no barriers to delivery, and whilst we do not know the quality of the IAQ verbal feedback provided, the IAQ written report was standardised. Also, our sample of imams interviewed $(n=6)$ and mosques where fidelity assessment was conducted $(n=6)$ was small. However, they were randomly selected, we captured some diversity in their interview accounts and intervention delivery, and the household data were confirmatory. We have no reason to think that other imams accounts or delivery would be markedly different.

\section{Why did the interventions not work?}

Features of success for both interventions were good acceptability, with good frequency of IAQ feedback and moderate to good SFH intervention delivery within Friday Jumu'ah prayers; at least in terms of what was prescribed and assessed. Reflections on the sufficiency of this prescribed frequency is discussed below. Moreover, imams reported no context barriers to delivery and important drivers (permission from the Islamic Foundation, support from the mosque) were in place. These positive findings are not unexpected. We engaged stakeholders in our intervention adaptation and development which is accepted good practice [16, 31]. The IAQ intervention was based on a format previously used in Europe [18-23] and carefully adapted for the Bangladesh context with household lead input; although with hindsight we should have considered more carefully how the report would be used by those who cannot read. The SFH intervention was developed using an iterative and collaborative approach (with the Islamic Foundation, imams and household leads) [27] to ensure that it was truly "a religiously inspired approach" [10, p1176] with acceptability and feasibility. Also, key lessons about intervention content (e.g., ensuring that the imams were credible "non-smoking" SHS messengers [8]) and delivery (e.g. support from mosque committees) were gathered from an earlier pilot trial of the SFH intervention in UK mosques [32]. These informed careful preparation work with mosques and imams to ensure they were ready for intervention delivery, a "success factor" of effective faith-based health promotion programmes [33].

Less positive were findings of poor reach of the SFH intervention and mixed quality of delivery. Only half of household leads recalled receiving the SFH intervention (or their family members receiving it). Imams reported sharing the Ayahs-messages in other mosque classes and congregations; however, there was 
little recollection of this amongst household leads. Although Friday prayers are traditionally attended by most Muslim men, the Khutbah sessions that are delivered before the prayers are not mandatory. Anecdotally, attendance may be as low as $10 \%$ of the total attendance in Friday prayers which may explain the poor reach. The emphasis in the imam training was to deliver the 12 weeks of Ayah-messages during the Khutbah sessions of the Jumu'ah prayers. With hindsight, we should probably have delivered Ayah-messages after Jumu'ah prayers or been more prescriptive about dissemination to other congregations, to increase frequency and reach. As an example, a "potentially effective" Korean churchbased intervention targeting SHS was more widely embedded across church activities that lasted up to 1.5 hours, with dissemination of multiple resources (SHS brochures, quit-smoking guides, SHS stickers, reusable grocery bags, and insulated lunch bags) [34].

Ayahs-messages targeting SHS attitudes and social norms were the self-declared focus of imams, with those targeting attitudes implemented most fully. These were also the Ayahs-messages recalled by household leads, resulting in new knowledge with a corresponding shift in their SHS attitudes, social norms and intentions to change their SHS behaviours. Interestingly it seemed to be the SHS health messages e.g. risks to their children, that were remembered rather than the corresponding religious text. That said, even if the men had remembered the religious connection in the SFH intervention, this will only have impacted on motivation [10]. Ayahs-messages targeting self-efficacy and planning were not remembered by household leads and were less well delivered. It seems likely that imams can confidently educate, whilst lacking skills to deliver strategies to turn knowledge into behaviour. The same outcome was evident for the IAQ intervention, with interview participants self-reporting learning about the risks of SHS in their own home, changing their attitudes, social norms and being motivated to create a SFH, yet plans for how to do this was absent in their accounts.

Despite the detailed behavioural science work underpinning both interventions, they were remembered by recipients as educational interventions. It seems likely that participants were ill-equipped to translate positive intentions into behaviour which would require them to overcome significant context barriers, for example, asking visitors to smoke outside or identifying somewhere to smoke outside. This hypothesis is consistent with a scoping review of fathers' views and experiences of creating a SFH [35] and European evaluation of an SFH intervention [21].Overall, it is unsurprising that there was a lack of perceived "usefulness in creating a SFH" for both interventions, and no effect on the self-reported SFH status in homes (confirmed by 24-h mean household airborne fine particulate matter ( $<2.5$ microns in diameter [PM2·5]) concentration) 12-months post-intervention [24].

Literature reviews [36-39] consistently conclude that there is promising evidence for faith-based health promotion interventions whilst at the same time identifying a need for more rigorous evaluation. Our SFH intervention comprised many of the "success factors" for effective faith-based programme [33]. There is also support for IAQ feedback interventions in Europe [17-23]. Our IAQ intervention was an adapted version of these European feedback tools, although our frequency was less than other programmes that incorporate repeat measurement, follow-up visits or phone calls [17-23]. What was different for both interventions is that we did not include one-to-one support for behaviour change which is evident in other 
faith-based programmes via motivational coaches [34], lay volunteers [33] or faith nurses [36]; or the motivational interview component that accompanied the IAQ report [17-23]. Within the smoking literature, a 2018 review concluded that the effectiveness of educational interventions in reducing SHS exposure was unclear [4]. Whereas combining SHS interventions with smoking cessation support may reduce SHS exposure [19]. The imams did deliver smoking cessation Ayah-messages alongside the SFH Ayah-messages, however personalised support was not provided.

Alturki [10] proposes that civil society including Muslim authorities should supplement smoking cessation programmes delivered by health professionals. Unfortunately, in Bangladesh, smoking cessation services are lacking, a situation that reflects poor implementation of the World Health Organization Framework Convention on Tobacco Control (FCTC) [40] Article 14 more widely across LMICs [41]. A further challenge is the weak implementation of SHS legislation (WHO FCTC Article 8) in Bangladesh, again consistent with other LMICs [41, 42]. The WHO [9] and other authors in this field [8, 10]. advocate a community-wide strategy where faith-based programmes are 'one part of a comprehensive overall approach to tobacco control' [9] including cessation services and good policy. Embedding our two interventions within this wider community approach would seem sensible. One example would be to link with the established network of community health workers who deliver primary care and behaviour change counselling services in Bangladesh, to achieve a "multiplier effect" [43].

\section{Conclusions}

Despite detailed development and adaption work with relevant stakeholders, the SFH and IAQ feedback interventions became educational interventions that were motivational but insufficient to overcome significant context barriers to SHS behaviour change. Embedding these interventions into community wide strategies that include practical cessation support and enforcement of SFH legislation is needed.

\section{Abbreviations}

\section{FCTC}

Framework Convention on Tobacco Control

IAQ

indoor air quality

LMIC

Low and middle-income countries

MCLASS

Muslim Communities Learning About SHS

SFH

Smoke-free homes

SHS

Second-hand smoke

WHO 


\section{Declarations}

\section{Ethics approval and consent to participate}

Ethics approval was obtained from the Bangladesh Medical Research Council's National Research Ethics Committee (BMBC/NREC/2016-2019/358) and the University of York's Health Sciences Research Governance Committee. Written informed consent was obtained from imams or khatibs for their and their mosques' participation, heads of household for participation of households, and adults in respective households for their own data collection.

\section{Consent for publication}

Not applicable

\section{Availability of data and material}

The datasets used and/or analysed during the current study are available from the corresponding author on reasonable request.

De-identified individual participant data will be made available from the point of, and up to 5 years after the acceptance for publication of the main findings from the final dataset. These data can be requested from the Principal Investigator (Prof Kamran Siddiqi; kamran.siddiqi@york.ac.uk) and will be shared after the provision of a methodologically sound proposal, and only under a data-sharing agreement that provides for commitment to: using the data only for research purposes and not to identify any individual participant; securing the data using appropriate computer technology; and destroying or returning the data after analyses are completed. The proposals will be assessed and approved by members of the Programme Management Group.

\section{Competing Interests}

The authors declare that they have no competing interests.

\section{Funding}

This trial was funded by the Medical Research Council UK under the Global Alliance for Chronic Diseases research programme (MR/P008941/1). The funder was not involved in the design of the study, collection, analysis, and interpretation of data or in writing the manuscript.

\section{Author's contributions}

CJ co-conceived, co-designed, and led the process evaluation and led the data analysis, data interpretation, and drafting of the manuscript. ZA co-designed the process evaluation, conducted data 
collection and data analysis, drafted some sections of the manuscript. IK co-conceived and co-designed the process evaluation and co-drafted the manuscript. NDM co-conceived the process evaluation and revised the manuscript. CF conducted data analysis and revised the manuscript. TF conducted data collection and revised the manuscript. $\mathrm{CH}$ conducted data analysis and revised the manuscript. RH coconceived the process evaluation, supervised data collection and revised the manuscript. AM, SS, AS and KS co-conceived the process evaluation and revised the manuscript. All authors approved the manuscript.

\section{Acknowledgements}

We would like to thank members of the independent trial steering committee: Dr Andrew Fogarty (Chair), and Professor Jo Leonardi-Bee, University of Nottingham, Nottingham, UK; and Dr Saidur Rahman Mashreky, Bangladesh University of Health Sciences, Dhaka, Bangladesh. Our gratitude also goes to members of our national-level reference group: Joint Secretary of the Ministry of Religious Affairs, Director of Research of the Islamic Foundation, Head of the Imam Training Academy, and a representative from ARK Foundation. We are also grateful to the project working group comprising an Islamic Foundation representative, an imam, a research fellow, a public health expert, and a member of the public. Finally thank you to the trial field investigators, the Islamic Foundation, participating mosques, their mosque committee leaders, imams, and khatibs; all participants; professionals and other researchers who have contributed to this trial.

\section{Additional Files}

Triangulation matrix for SFH intervention

Triangulation matrix for IAQ feedback

\section{References}

1. Öberg M, Jaakkola MS, Woodward A, Peruga A, Prüss-Ustün A. Worldwide burden of disease from exposure to second-hand smoke: a retrospective analysis of data from 192 countries. Lancet. 2011;377:139-46.

2. Ferdous T, Siddiqi K, Semple S, Fairhurst C, Dobson R, Mdege N, et al. Smoking behaviours and indoor air quality: a comparative analysis of smoking-permitted versus smoke-free homes in Dhaka, Bangladesh. Tob. Control. 2020;Dec 16;tobaccocontrol-2020-055969 [Epub ahead of print].

3. Shah SK, Kanaan M, Huque R, Sheikh S, Dogar OF, Thomson H, et al. Secondhand smoke exposure in primary school children: a survey in Dhaka, Bangladesh. Nicotine Tob Res. 2019;21:416-23.

4. Behbod B, Sharma M, Baxi R, Roseby R, Webster P. Family and carer smoking control programmes for reducing children's exposure to environmental tobacco smoke. Cochrane Database of Systematic Reviews. 2018;1:CD00174.

5. Dherani M, Zehra SN, Jackson C, Satyanaryana V, Huque R, Chandra P, et al. Behaviour change interventions to reduce second-hand smoke exposure at home in pregnant women - a systematic 
review and intervention appraisal. BMC Pregnancy and Childbirth. 2017;17:378.

6. Tong TV, Dietz PM, Rolle IV, Kennedy SM, Thomas W, England LJ. Clinical interventions to reduce secondhand smoke exposure among pregnant women: a systematic review. Tob Control. 2015;24:217-23.

7. Nunziata L, Toffolutti. "Thou Shalt not Smoke”: Religion and smoking in a natural experiment of history. SSM-Popula Health. 2019;8:1004012.

8. Byron MJ, Cohen JE, Gittelsohn J, Frattaroli S, Nuryunawati R, Jernigan DH. Influence of religious organisations' statements on compliance with a smoke-free law in Bogor, Indonesia: a qualitative study. BMJ Open. 2015;5:e008111.

9. World Health Organization. Tobacco Use and Religion. Cairo: WHO Regional Office for the Eastern Mediterranean; 2014.

10. Alturki K, Hamza A, Walton P. Islam and Motivation to Quit Smoking: Public Health Policy Implications. J Relig Health. 2020;59:1175-88.

11. Garrusi B, Nakhaee N. Religion and smoking: A review of recent literature. Int J Psychiatry Med. 2012;43:279-29.

12. Mustafa Y, Baker D, Puligari P, Melody T, Yeung J, Gao-Smith F. The role of imams and mosques in health promotion in Western societies-a systematic review protocol. BMC Syst Rev. 2017;6:25.

13. Radwan GN, Israel E, El-Setouhy M, Abdel-Aziz F, Mikhail N, Mohamed MK. Impact of religious rulings (fatwa) on smoking. J Egypt Soc Parasitol 2003;33:1087-101.

14. Cultural Atlas. Bangladeshi Culture. https://culturalatlas.sbs.com.au/bangladeshiculture/bangladeshi-culture-religion. Accessed 3 October 2021.

15. Liu JJ, Davidson E, Bhopal RS, White M, Johnson MRD, Netto G, et al. Adapting health promotion interventions to meet the needs of ethnic minority groups: mixed-methods evidence synthesis. Health Technol Assess. 2012;16:1-469.

16. Liu JJ, Wabnitz C, Davidson E, Bhopal RS, White M, Johnson MR, et al. Smoking cessation interventions for ethnic minority groups-A systematic review of adapted interventions. Prev. Med. 2013;57:765-75.

17. Harutyunyan A, Movsisyan N, Petrosyan V, Petrosyan D, Stillman. Reducing children's exposure to secondhand smoke at home: a randomized trial. Pediatrics. 2013;132:1071-80.

18. Wilson I, Semple S, Mills LM, Ritchie D, Shaw A, O'Donnell R et al. REFRESH-reducing families' exposure to secondhand smoke in the home: a feasibility study. Tob Control 2013;22:e8.

19. Ratschen E, Thorley R, Jones L, Opazo Breton M, Cook J, McNeill A. A randomised controlled trial of a complex intervention to reduce children's exposure to secondhand smoke in the home. Tob Control. 2018;27:155-62.

20. Hughes SC, Bellettiere J, Nguyen B, Liles S, Klepeis NE, Qunitana PJE, et al. Randomized Trial to Reduce Air Particle Levels in Homes of Smokers and Children. Am J Prev Med. 2018;54:359-67. 
21. Dobson R, O'Donnell R, Tigova O, Fu M, Enriquez M, Fernandez E et al. Measuring for change: A multicentre pre-post trial of an air quality feedback intervention to promote smoke-free homes. Environ Int. 2020;140:105738.

22. Dobson $\mathrm{R}$, O'Donnell $\mathrm{R}$, de Bruin $\mathrm{M}$, Turner $\mathrm{S}$, Semple $\mathrm{S}$. Using air quality monitoring to reduce second-hand smoke exposure in homes: the AFRESH feasibility study. Tob Prev Cessat. 2017;3:117.

23. Semple S, Turner S, O'Donnell R, Adams L, Henderson T, Mitchell S, et al. Using air-quality feedback to encourage disadvantaged parents to create a smoke-free home: Results from a randomised controlled trial. Environ Int. 2018;120:104-10.

24. Mdege ND, Fairhurst C, Ferdous T; Hewitt C, Huque R, Jackson C, et al. Muslim Communities Learning About Second-hand Smoke in Bangladesh (MCLASS II): study protocol for a cluster randomised controlled trial of a community-based smoke-free homes intervention, with or without Indoor Air Quality feedback. Trials. 2019;20:11.

25. Mdege ND, Fairhurst C, Wang Han-I, Ferdous T, Marshall AM, Hewitt C, et al. Muslim Communities Learning About Second-hand Smoke in Bangladesh (MCLASS II): a three-arm, cluster randomised controlled trial of the effectiveness and cost-effectiveness of a community-based smoke-free homes intervention, with or without indoor air quality feedback. Lancet Glob Health. 2021;9:e639-50.

26. Medical Research Council. Process evaluation of complex evaluations. London: Medical Research Council; 2015.

27. Kellar I, Azdi AA, Jackson C, Huque R, Dadirai Mdege N, et al. Muslim Communities Learning About Second-hand Smoke in Bangladesh (MCLASS II): a combined evidence and theory-based plus partnership intervention development approach. https://www.researchsquare.com/article/rs944654/v1. Accessed 26 October 2021.

28. World Health Organization. Exposure to household air pollution for 2016. Last modified 2018. https://www.who.int/airpollution/data/HAP_exposure_results_final.pdf?ua=1. Accessed 3 October 2021.

29. 0 Cathain A. A Practical Guide to Using Qualitative Research with Randomized Controlled Trials. Oxford: Oxford University Press; 2018.

30. Ritchie J, Lewis J, McNaughton Nicholls C, Ormston R. Qualitative Research Practice. London: SAGE; 2014.

31. Vu M, Muhammad H, Peek ME, Padela Al. Muslim women's perspectives on designing mosque-based women's health interventions-an exploratory qualitative study. Women Health. 2018;58:334-46.

32. King R, Warsi AS, Amos S, Shah S, Mir G, Sheikh A et al. Involving mosques in health promotion programmes: a qualitative exploration of the MCLASS intervention on smoking in the home. Health Educ Res. 2017;32 293-305.

33. Sternberg Z, Munschauer FE, Carrow SS, Sternberg E, Faith-placed cardiovascular health promotion: a framework for contextual and organizational factors underlying program success. Health Educ Res. 2007;22:619-29. 
34. Hughes SC, Corcos I, Hovell M, Hofstetter CR. Feasibility Pilot of a Randomized Faith-Based Intervention to Reduce Secondhand Smoke Exposure Among Korean Americans. Prev Chronic Dis. 2017;14:1-8.

35. O'Donnell R, Angus K, McCulloch P, Amos A, Greaves L, Semple S. Fathers' Views and Experiences of Creating a Smoke-Free Home: A Scoping Review. Int J Environ Res Public Health. 2019;16:5164.

36. Bopp M, Peterson JA, Webb BL. A comprehensive review of faith-based physical activity interventions. Am J Lifestyle Med. 2012;6:460-78.

37. Parra MT, Porfírio GJM, Arredondo EM, Atallah ÁN. Physical Activity Interventions in Faith-Based Organizations: A Systematic Review. Am J Health Promot. 2018;32:677-90.

38. DeHaven MJ, Hunter IB, Wilder L, Walton JW, Berry J. Health Programs in Faith-Based Organizations: Are They Effective? Am J Pub Health. 2004;94:1030-36.

39. Lancaster KJ, Carter-Edwards L, Grilo S, Shen C, Schoenthaler AM. Obesity interventions in African American faith-based organizations: a systematic review. Obes Rev. 2014;15(suppl 4):159-76.

40. World Health Organization. WHO Framework Convention of Tobacco Control. https://fctc.who.int/ Accessed 26 October 2021.

41. Nilan K, Raw M, McKeever TM, Murray RL, McNeill A. Progress in implementation of WHO FCTC Article 14 and its guidelines: a survey of tobacco dependence treatment provision in 142 countries. Addiction. 2017;112:2023-31.

42. Nazar GP. Smoke-free legislation and active smoking, second hand exposure and health outcomes in low- and middle-income countries. PhD thesis, London School of Hygiene and Tropical Medicine. https://researchonline.Ishtm.ac.uk/id/eprint/4433694/ Accessed 8 October 2021.

43. Ahmed S, Khan JAM. Disseminating public health messages about second-hand smoking through mosque congregations in Bangladesh. Lancet. 2021;9:e657-58.

\section{Figures}


The SFH intervention consisted of a set of health messages relating to smoking and SHS exposure, each supported by at least one verse (Ayah) from the Qur'an, or an Islamic faith-based decree. The messages were developed through a set of iterative workshops involving Islamic scholars, public health professionals and behavioural scientists [27]. They addressed key barriers and drivers of smoking behaviours (attitudes, self-efficacy, social norms, intention formation, action and coping planning, see Figure 2). Imams and khatibs were trained in a half-day session on the intervention and its delivery including detailed guidance on linking the messages and Ayahs. They then delivered the messages and Ayahs in the form of Khutbah (public preaching in the Islamic tradition) to those attending Friday Jumu'ah prayer in 30 mosques over 12 weeks (one linked Ayah-message per week). They also distributed copies of a short SFH booklet to their congregation.

The IAQ feedback was delivered, in addition to the SFH intervention, to households from 16 of the 30 mosques. Twelve field investigators provided households with personalised information on the air quality (PM2.5 concentration) measured within their home at baseline using the Dylos DC 1700 (Dylos, California, USA), an optical particle counter validated for use in domestic settings. Feedback comprised a comparison of the 24-hour mean $\mathrm{PM}_{2.5}$ concentration measured in the home to the World Health Organization (WHO) guidance limit of $25 \mu \mathrm{g} / \mathrm{m}^{3}$ [28], the total time the IAQ was above this guidance limit, and the maximum concentration measured during the 24-hour measurement period. It included graphical information on how smoking activity impacted on IAQ over the 24-hour measurement period (with classifications: hazardous if $>150 \mu \mathrm{g} / \mathrm{m}^{3}$, unhealthy if $36-150 \mu \mathrm{g} / \mathrm{m}^{3}$, moderate if $12-35 \mu \mathrm{g} / \mathrm{m}^{3}$, and good if $<12 \mu \mathrm{g} / \mathrm{m}^{3}$ ), information about the adverse effects of SHS exposure, recommendations to reduce SHS exposure in the home, and a target that was achievable by implementing SFH rules within the home. This information was presented in a two-page bespoke leaflet designed in consultation with community members. Trial field investigators delivered and discussed the IAQ feedback with members of the households in person in approximately 10 minutes.

Both the SFH manual and IAQ feedback leaflet are available here Muslim Communities Learning About Secondhand Smoke in Bangladesh (MCLASS II) - Health Sciences, University of York.

\section{Figure 1}

Description of the SFH and IAQ feedback interventions 


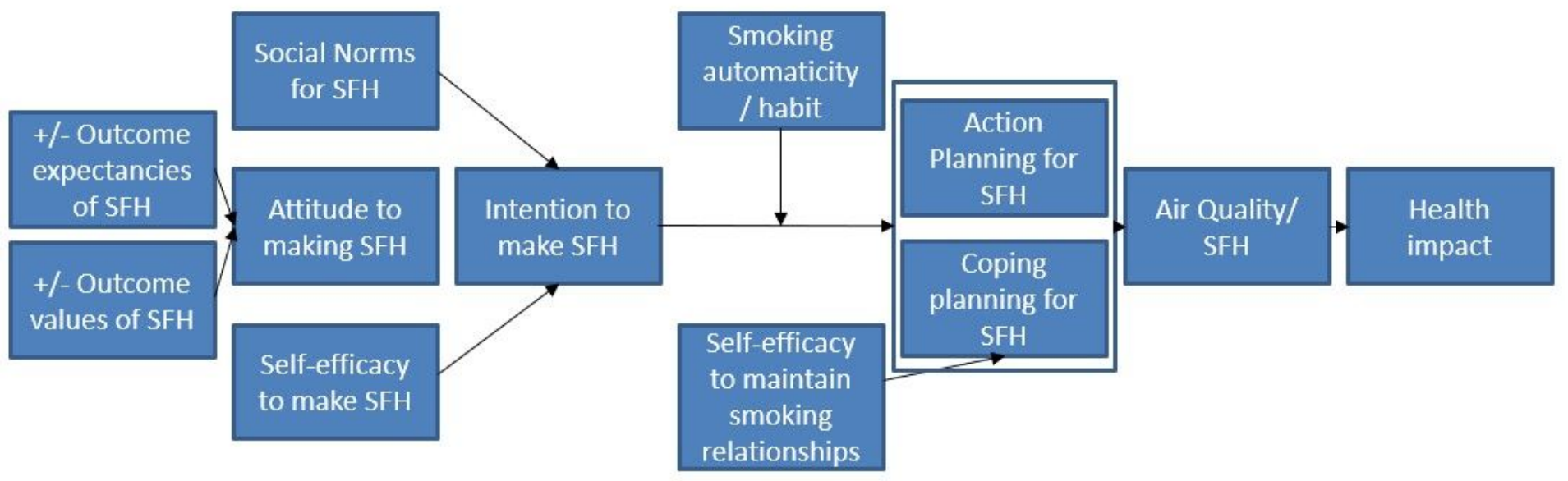

\section{Figure 2}

Intervention Programme Theory

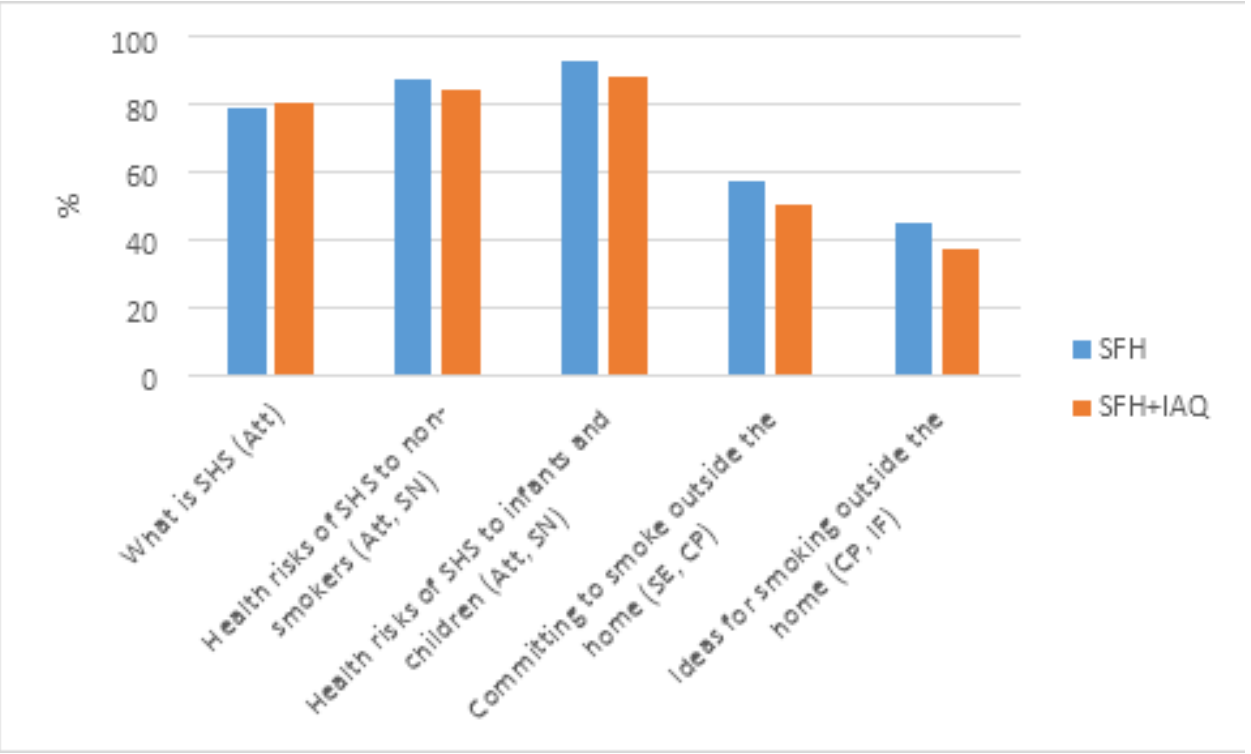

\section{Figure 3}

Percentage recall (reach) of SFH intervention Ayahs-messages by men who had received the SFH intervention Note. Att=attitude, $\mathrm{SN}=$ social norm, $\mathrm{SE}=$ self-efficacy, $\mathrm{CP}=$ coping planning, IF=intention formation 


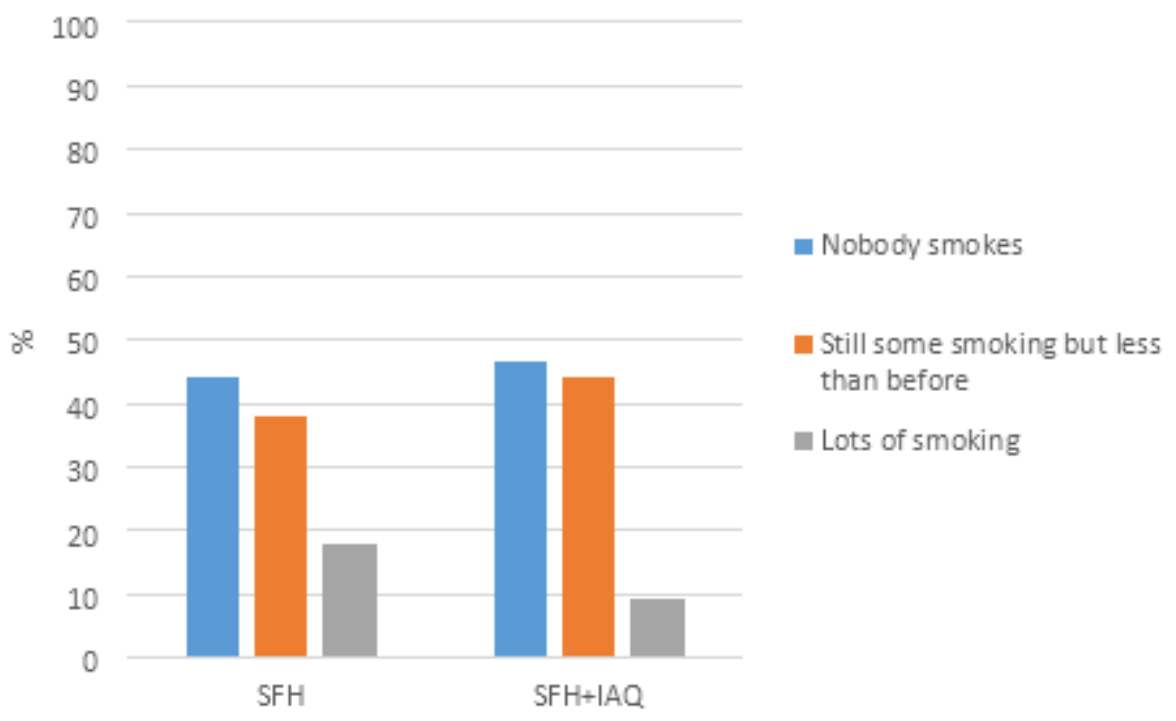

Figure 4

Self-reported SFH status at 3-month post-intervention

\section{Supplementary Files}

This is a list of supplementary files associated with this preprint. Click to download.

- MCLASSIlprocessevaluationAdditionalFile1SUBMITTED.docx

- MCLASSIlprocessevaluationAdditionalFile2SUBMITTED.docx 